\title{
BMJ Open Disparities in road crash mortality among pedestrians using wheelchairs in the USA: results of a capture-recapture analysis
}

\author{
John D Kraemer, ${ }^{1}$ Connor S Benton ${ }^{2}$
}

To cite: Kraemer JD, Benton CS. Disparities in road crash mortality among pedestrians using wheelchairs in the USA: results of a capture-recapture analysis. BMJ Open 2015;5: e008396. doi:10.1136/ bmjopen-2015-008396

\section{- Prepublication history and additional material is available. To view please visit the journal (http://dx.doi.org/ 10.1136/bmjopen-2015- 008396).}

Received 2 April 2015

Revised 10 August 2015

Accepted 18 September 2015

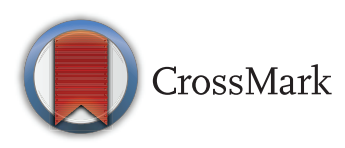

${ }^{1}$ Department of Health Systems Administration, O'Neill Institute for National and Global Health Law, Georgetown University, Washington DC, USA ${ }^{2}$ School of Medicine, Georgetown University, Washington DC, USA

Correspondence to Professor John D Kraemer; jdk32@georgetown.edu

\section{ABSTRACT}

Objective: This study aims to quantify and describe the burden of fatal pedestrian crashes among persons using wheelchairs in the USA from 2006 to 2012.

Design: The occurrence of fatal pedestrian crashes among pedestrians using wheelchairs was assessed using two-source capture-recapture. Descriptive analysis of fatal crashes was conducted using customary approaches.

Setting: Two registries were constructed, both of which likely undercounted fatalities among pedestrians who use wheelchairs. The first used data from the Fatality Analysis Reporting System, and the second used a LexisNexis news search.

Outcome measures: Mortality rate (per 100000 person-years) and crash-level, driver-level and pedestrian-level characteristics of fatal crashes.

Results: This study found that, from 2006 to 2012, the mortality rate for pedestrians using wheelchairs was $2.07 / 100000$ person-years $(95 \% \mathrm{Cl} 1.60$ to 2.54$)$, which was $36 \%$ higher than the overall population pedestrian mortality rate $(p=0.02)$. Men's risk was over fivefold higher than women's risk $(p<0.001)$. Compared to the overall population, persons aged 50-64 using wheelchairs had a 38\% increased risk $(p=0.04)$, and men who use wheelchairs aged 50-64 had a $75 \%$ increased risk over men of the same age in the overall population $(p=0.006)$. Almost half $(47.6 \%$; $95 \% \mathrm{Cl} 42.8$ to 52.5 ) of fatal crashes occurred in intersections and $38.7 \%(95 \% \mathrm{Cl} 32.0$ to 45.0$)$ of intersection crashes occurred at locations without traffic control devices. Among intersection crashes, $47.5 \%(95 \%$ Cl 40.6 to 54.5$)$ involved wheelchair users in a crosswalk; no crosswalk was available for $18.3 \%$ (95\% Cl 13.5 to 24.4). Driver failure to yield right-of-way was noted in $21.4 \%(95 \% \mathrm{Cl} 17.7$ to 25.7) of crashes, and no crash avoidance manoeuvers were detected in $76.4 \%$ (95\% $\mathrm{Cl} 71.0$ to 81.2$)$.

Conclusions: Persons who use wheelchairs experience substantial pedestrian mortality disparities calling for behavioural and built environment interventions.

\section{INTRODUCTION}

Reducing the public health burden from pedestrian crashes is a top road safety

\section{Strengths and limitations of this study}

- This is the first time pedestrian mortality rates have been calculated for this population or compared to the general population, and it identifies a substantial disparity in injury risk.

- The main findings are robust to potential misestimation of the size of the population that uses wheelchairs in the USA.

- The main findings are also robust to potential misestimation of the overall population's pedestrian mortality rate.

- Two source capture-recapture is reliant on assumptions which can only be partially tested, which is a principal limitation of this study.

- There is a possibility of underestimation of wheelchair user deaths because persons identified in new stories as using 'scooters' were excluded because mobility devices could sometimes not be distinguished from recreational scooters or mopeds. This would result in a conservative estimate of fatalities.

priority. Each year, nearly 5000 pedestrians are killed and another 76000 are injured by crashes on public roadways in the USA. ${ }^{1}{ }^{2}$ Although both domestic ${ }^{3} 4$ and international $^{5}$ policies require pedestrian infrastructure to enable safe and effective use by persons with disabilities, pedestrian injury risk among this population has been little studied. Improved safety for pedestrians using wheelchairs is, however, an advocacy organisation priority, both because of direct injury risks and because safety hazards impede persons with disabilities from being able to fully use the communities in which they live and work. ${ }^{6}$

Existing research has principally focused on non-fatal injuries among pedestrians using wheelchairs. A recent study found an incidence rate of pedestrian injury among persons using wheelchairs between 2002 and 2010 of 31.3/100 000 person-years (py), with 
men having a 3.5-fold increased risk over women. ${ }^{7}$ Earlier research found broadly similar results, and the gender disparity has been identified consistently in prior research. ${ }^{8-12}$

Mortality, however, has been identified as needing further study. ${ }^{7}$ A National Highway Traffic Safety Administration (NHTSA) analysis of emergency department (ED) visits found approximately 1 death per 40 non-fatal crashes among pedestrians using wheelchairs between 1991 and 1995. However, ED records undercount fatalities, which often occur at the crash scene, and this study was based on a small sample of deaths. ${ }^{9}$ Another analysis examined news reports of pedestrian crashes involving wheelchair users and found that over half of reported crashes were fatal; ${ }^{10}$ however, news sources under-report non-fatal crashes. ${ }^{13}$ Further, causes of fatal pedestrian crashes among wheelchair users have not been deeply assessed, though low night-time conspicuity has been hypothesised through a well-designed case study and literature review. ${ }^{8}$ Others have hypothesised that built-environment factors, such as safe and accessible crossings, likely play a role in collisions. ${ }^{7}$

This study has two objectives. First, using two-source capture-recapture, it seeks to estimate and describe the pedestrian crash mortality burden among wheelchair users by examining overlapping capture between two incomplete data sources. Second, it describes environmental, driver-level and pedestrian-related characteristics of crashes that killed pedestrians who used wheelchairs.

\section{METHODS}

\section{Data sources}

Two independent registries of fatal crashes involving pedestrians using wheelchairs from 2006 to 2012 were constructed. The first registry used data in NHTSA's Fatality Analysis Reporting System (FARS), a census of road crashes that occur on US public trafficways and produce at least one fatality within 30 days. FARS is based on police reports and fully described elsewhere. ${ }^{14}$ While FARS seeks to fully capture fatal crashes, preliminary assessment of its data suggested incomplete ascertainment of wheelchair use, rendering it an incomplete source for identifying fatal crashes among pedestrians who use wheelchairs. A crash was included if a killed non-vehicle occupant was identified as 'restricted to a wheelchair' or a motorised wheelchair rider and one of the following non-occupant types: pedestrian, non-motor vehicle transport device occupant or person using a personal conveyance. Individuals who otherwise met the inclusion criteria but endured non-fatal injury were excluded.

The second registry was constructed by searching the LexisNexis US newspaper database with the following search term: HEADLINE (wheelchair or wheel chair) and (kill! or die! or death! or dead or fatal) and (car or truck or vehicle or road or street or highway or crosswalk or van or crash or accident or strike! or struck or hit). Each identified article was reviewed for relevance and included if it described a crash on a public trafficway that killed a pedestrian using a wheelchair. Articles were abstracted for information sufficient for matching (including crash and death date, time, and location; age, sex, and race; and a narrative summary). Abstraction was conducted by one author and visually checked by the other.

For capture-recapture estimation, fatal crashes in the two registries were matched if they occurred in the same location on the same date, and if the victim's age and sex matched. Minor variation in age and date were tolerated if (1) the news story's crash street address matched the FARS global positioning system (GPS) crash coordinates and (2) there were other reliable indicia that the registry entries corresponded, such as matching crash time of day and news story crash narratives that corresponded to the crash event sequence recorded in FARS.

After capture-recapture matching and estimation of the number of fatalities, unmatched cases included in the news story registry were sought in the general FARS database. Because the FARS-based registry's incompleteness resulted primarily from incomplete ascertainment of wheelchair use-not missing crash episodes-almost all unmatched cases could be identified in FARS as pedestrian crashes that failed to code the pedestrian as using a wheelchair (with 252 of the total of 255 identified cases ultimately identifiable in FARS). Thus, without compromising the FARS wheelchair crash registry's independence from the news registry, it was possible to create a combined listing of crashes that incorporated all relevant FARS variables. Assuming that identified cases represent those that were calculated to exist by capture-recapture but unidentified (testing for which is described below), the combined listing is a sample of the overall population of fatal pedestrian crashes among wheelchair users. This sample was used for further descriptive analyses.

Rate calculations used denominator data-the number of persons using wheelchairs in the USA — which came from the Census Bureau's Survey of Income and Program Participation (SIPP), which is fully described elsewhere. ${ }^{15}$ SIPP is a population-representative survey of noninstitutionalised persons, and it has a periodic disability module that includes wheelchair use items. Estimates were calculated from these items using sampling weights, with SEs adjusted for the complex sampling approach using Fay's method with balanced repeated replication or Taylor linearisation, depending on how the data were structured each survey year. ${ }^{16}$ SIPP wheelchair use data are available for 2002, 2003, 2005 and 2010, so denominators for other years were calculated by geometric extrapolation from the nearest years, which assumes a constant rate of population change. ${ }^{7}$

For comparison purposes, pedestrian death risk in the general US population was determined by querying CDC's WISQARS fatal injury report database, ${ }^{17}$ which derives from the National Vital Statistics System (NVSS) census of death certificate records and is fully described elsewhere. ${ }^{18}$ 


\section{Variables}

For the capture-recapture analysis, pedestrians' sex and age and the crash year were the primary categories of interest. Race and ethnicity were also tabulated but ultimately discarded because data were frequently missing. Age was categorised (under 30 years, 30-49, 50-64, and 65 and above) to maintain sample size, and under-30 deaths are not shown because very small samples made estimates unstable. Sex-stratified estimates were shown by age for men but not women because female samples were too small to produce stable estimates.

For the descriptive analysis of crashes, standard FARS variables were used. FARS variable definitions are available publicly. ${ }^{14}$ Crash-level variables included day of the week, time of day, light conditions, weather conditions, roadway function class at the crash site, urban versus rural crash locale, traffic control devices present, and whether or not the crash occurred at an intersection. Driver and vehicle-level variables included drivers' sex and age, striking vehicle type and police-reported substance use. Various driving behaviours were distilled from four FARS driver-related factors fields, and cited violations were distilled from the relevant FARS items, as were crash avoidance manoeuvers.

Pedestrian-level characteristics included sex, age and race/ethnicity. Additional variables included policereported substance use, crosswalk use (stratified on whether the crash occurred in an intersection), whether the pedestrian died at the scene or after transport, and wheelchair type. A wheelchair was coded as electric if a news report referenced an electric wheelchair, an accompanying photo made clear that the pedestrian was using an electric wheelchair, or if the FARS record noted that the pedestrian was using a motorised wheelchair.

\section{Statistical methods}

The number and SD of pedestrian fatalities among wheelchair users-both overall and within age and sex strata-were calculated via two-sample capture-recapture estimation using Chapman's method, ${ }^{19-23}$ which corrects for potential bias from small samples. To calculate mortality rates, the number of deaths determined via capture-recapture was divided by the number of personyears of wheelchair use from SIPP data. The rate of pedestrian mortality in the overall US population was identified by querying WISQARS with exact CIs calculated. $p$ Values for the difference in rates between pedestrians using wheelchairs and the overall population were calculated using z-tests for differences. $p$ Values equal to or below 0.05 and 0.10 were considered significant and marginally significant, respectively.

Capture-recapture assumes that cases in each registry represent the same underlying population, but captured incompletely. ${ }^{24} 25$ This assumption was tested by assessing differences in the proportion of commonly reported characteristics between cases identified via
FARS and news searches using a t test (continuous variables) or Fischer's exact test (categorical variables).

Descriptive analysis was conducted on all records that could be identified in FARS (whether they were originally coded in FARS as a wheelchair-related crash or subsequently identified as a non-wheelchair-coded FARS pedestrian case). For this analysis, standard descriptive approaches were used, with a finite population correction set to the capture-recapture estimate's 95 CI's upper bound: 647 deaths. Analyses used Stata V.13.1.

\section{Sensitivity analyses}

The rate of deaths among pedestrians using wheelchairs is potentially sensitive to how the denominator-the number of persons using wheelchairs-was extrapolated from years for which SIPP data were available, so alternate approaches were tested: linear interpolation between the two nearest years or extrapolation past the nearest year; fitting a quadratic equation using OLS; and estimating a $\log$-linear relationship by fitting a generalised linear model with a log link. To guard against sampling error in the SIPP estimates, an additional analysis used the same extrapolation approach as in the main analysis, but conservatively based point estimates on the upper bound of the SIPP estimates' one-sided 95\% CI.

Two additional sensitivity analyses used alternative means of estimating pedestrian mortality in the overall population for comparison purposes. One increased the annual number of deaths in WISQARS by $5 \%$, which is slightly more than the annual average percentage of injury deaths with an unspecified mechanism recorded on the death certificate. ${ }^{26} 27$ The second instead used all deaths in the FARS census classified as pedestrians, persons using personal conveyances or non-motor vehicle transport devices, and non-vehicle-occupants of unknown type.

Georgetown University's IRB did not require study approval because there was no interaction with living persons or use of non-public information.

\section{RESULTS}

\section{Main results}

The news registry included 107 fatal crashes among pedestrians using wheelchairs, and the FARS registry included 185. Of these, 37 were included in both registries, yielding an estimated 528 fatalities (95\% CI 409 to 627) (table 1) during 25.5 million py at risk. This equals a mortality rate (MR) from pedestrian crashes of 2.07/ 100000 py (95\% CI 1.60 to 2.54 ), a risk about one-third higher than in the overall population $(p=0.02)$. Risk of pedestrian crash death was significantly higher for men using wheelchairs $(3.95 / 100000$ py; $95 \%$ CI 2.96 to 4.93) than women $(0.73$ per 100000 py; $95 \%$ CI 0.40 to 1.06). The risk for male wheelchair users was higher than in the overall male population $(p<0.001)$, but women's risk did not significantly vary from the overall female population $(\mathrm{p}=0.28)$. 


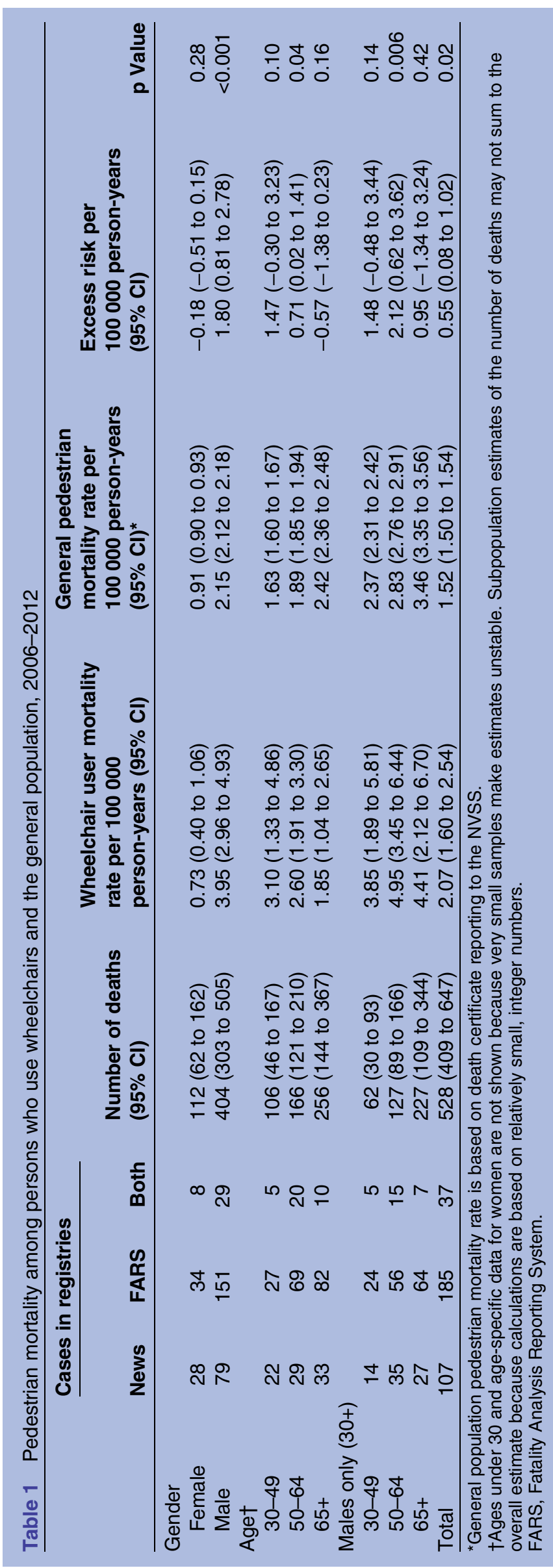

Mortality risk was most elevated among relatively young and middle-aged pedestrians who used wheelchairs. The MR of pedestrian death was 3.10/100 000 py (95\% CI 1.33 to 4.86 ) for wheelchair users aged 30-49, which was approximately double the risk among the overall population of 30-49 year olds but only marginally significant $(p=0.10)$. Among those $50-64$ years old, the risk of death $(\mathrm{MR}=2.60 / 100000 \mathrm{py} ; 95 \%$ CI 1.91 to $3.30)$ was $38 \%$ higher $(\mathrm{p}=0.04)$. Men aged $50-64$ years who use wheelchairs were at particularly high risk of pedestrian death $(\mathrm{MR}=4.95 / 100000$ py; $95 \%$ CI 3.45 to 6.44) compared to equivalently aged men who do not use wheelchairs $(\mathrm{p}=0.006)$.

Deeper analysis was conducted on the 252 crashes that could ultimately be identified in FARS. Crash-level characteristics are described in table 2. Of note, over half of fatal crashes occurred on arterial roadways. Approximately half (47.6\%; $95 \%$ CI 42.8 to 52.5 ) occurred in intersections and $38.7 \%$ (95\% CI 32.0 to 45.0 ) of intersection crashes occurred at locations with no traffic control devices. Most crashes $(89.2 \%$; 95\% CI 85.7 to 91.9$)$ occurred during fair weather conditions, and about half occurred during full daylight (47.6\%; 95\% CI 42.8 to 52.5$)$.

Driver-level characteristics are reported in table 3 . Male drivers were involved in $74.8 \%$ (95\% CI 70.0 to 79.0) of crashes. Alcohol or drug use was reported in $9.1 \%$ (95\% CI 6.7 to 12.3 ) of crashes, and the most commonly reported behavioural factors were failure to yield the right-of-way (21.4\%; 95\% CI 17.7 to 25.7$)$ and inappropriate speed $(6.7 \%$; $95 \%$ CI 4.7 to 9.6$)$. In $76.4 \%$ (95\% CI 71.0 to 81.2 ) of crashes, no crash avoidance manoeuvers were detected.

Pedestrian-level characteristics are shown in table 4 . Males represent about three-quarters $(78.6 \%$; $95 \%$ CI 74.3 to 82.3 ) of deaths. $47.5 \%$ (95\% CI 40.6 to 54.5 ) of fatal intersection crashes involved wheelchair users in a crosswalk; no crosswalk was available for $18.3 \%$ (95\% CI 13.5 to 24.4). Few non-intersection crashes involved pedestrians in crosswalks $(4.5 \%$; 95\% CI 2.4 to 8.3$)$, though $22.7 \%$ (95\% CI 17.6 to 28.8 ) of non-intersection crashes occurred in places with unavailable crosswalks. Improper crossing or failure to yield the right-of-way was as a contributory cause in $36.2 \%$ (95\% CI 31.6 to 41.1 ) of fatal crashes. Police reported pedestrians' alcohol or drug use in $11.5 \%$ of crashes (95\% CI 8.8 to 15.0 ). Over one-quarter (26.2\%; $95 \%$ CI 22.2 to 30.7 ) of fatally struck pedestrians died on-scene.

\section{Sensitivity analyses and model assumptions}

Cases identified through FARS and news searches were not significantly different with respect to any tested feature (see online supplementary table S1). One variable-age-was marginally significantly different, with a mean age of 61.8 and 58.5 for FARS and news cases, respectively $(\mathrm{p}=0.10)$. With six independent tests, it was $47 \%$ likely that at least one marginally significant result would be observed by chance. 
Table 2 Crash-level characteristics

\begin{tabular}{|c|c|c|}
\hline & $\mathbf{n}$ & $\%(95 \% \mathrm{Cl})$ \\
\hline \multicolumn{3}{|l|}{ Light conditions } \\
\hline Daylight & $120 / 252$ & $47.6(42.8$ to 52.5$)$ \\
\hline Dark & $120 / 252$ & $47.6(42.8$ to 52.5$)$ \\
\hline Dusk/Dawn & $12 / 252$ & $4.8(3.1$ to 7.3$)$ \\
\hline \multicolumn{3}{|l|}{ Weather } \\
\hline No adverse & $223 / 250$ & $89.2(85.7$ to 91.9$)$ \\
\hline Rain & $24 / 250$ & $9.6(7.1$ to 12.9$)$ \\
\hline Snow & $2 / 250$ & $0.8(0.3$ to 2.4$)$ \\
\hline Fog or smoke & $1 / 250$ & $0.4(0.1$ to 1.9$)$ \\
\hline \multicolumn{3}{|l|}{ Roadway function } \\
\hline Principal arterial & $98 / 251$ & 39.0 (34.4 to 43.9$)$ \\
\hline Minor arterial & $70 / 251$ & 27.9 (23.7 to 32.5$)$ \\
\hline Collector & $20 / 251$ & $8.0(5.7$ to 11.0$)$ \\
\hline Local road/street & $63 / 251$ & $25.1(21.1$ to 29.6$)$ \\
\hline \multicolumn{3}{|l|}{ Intersection } \\
\hline In intersection & $120 / 252$ & $47.6(42.8$ to 52.5$)$ \\
\hline Not in intersection & $132 / 252$ & 52.4 (47.5 to 57.2$)$ \\
\hline \multicolumn{3}{|c|}{ Traffic control device: intersection crashes } \\
\hline None & $46 / 119$ & 38.7 (32.0 to 45.7$)$ \\
\hline $\begin{array}{l}\text { Signal with pedestrian } \\
\text { control }\end{array}$ & $25 / 119$ & $21.0(15.8$ to 27.4$)$ \\
\hline $\begin{array}{l}\text { Signal without pedestrian } \\
\text { control }\end{array}$ & $30 / 119$ & 25.2 (19.6 to 31.8$)$ \\
\hline Sign & $18 / 119$ & 15.1 (10.7 to 20.9$)$ \\
\hline \multicolumn{3}{|c|}{ Traffic control device: non-intersection crashes } \\
\hline None & $113 / 130$ & 86.9 (81.6 to 90.9$)$ \\
\hline $\begin{array}{l}\text { Signal without pedestrian } \\
\text { control }\end{array}$ & $5 / 130$ & $3.9(1.9$ to 7.5$)$ \\
\hline Sign & $12 / 130$ & $9.2(6.0$ to 14.0$)$ \\
\hline \multicolumn{3}{|l|}{ Urban setting } \\
\hline Urban & $218 / 251$ & 86.9 (83.2 to 89.8$)$ \\
\hline Rural & $33 / 251$ & $13.1(10.2$ to 16.8$)$ \\
\hline \multicolumn{3}{|l|}{ Day of week } \\
\hline Weekday & $195 / 252$ & 77.4 (73.1 to 81.2$)$ \\
\hline Weekend & $57 / 252$ & 22.6 (18.8 to 26.9 ) \\
\hline \multicolumn{3}{|l|}{ Time of day } \\
\hline $\begin{array}{l}\text { Morning rush hour: } \\
\text { 7:00-9:29 }\end{array}$ & $27 / 251$ & $10.8(8.1$ to 14.2$)$ \\
\hline $\begin{array}{l}\text { Late morning: } \\
9: 30-11: 59\end{array}$ & $22 / 251$ & $8.8(6.4$ to 11.9$)$ \\
\hline $\begin{array}{l}\text { Early afternoon: } \\
\text { 12:00-16:29 }\end{array}$ & $56 / 251$ & 22.3 (18.5 to 26.6 ) \\
\hline $\begin{array}{l}\text { Evening rush hour: } \\
\text { 16:30-18:59 }\end{array}$ & $42 / 251$ & 16.7 (13.4 to 20.7$)$ \\
\hline Evening:19:00-21:59 & $59 / 251$ & 23.5 (19.6 to 27.9 ) \\
\hline Late night: $22: 00-1: 59$ & $27 / 251$ & 10.8 (8.1 to 14.2$)$ \\
\hline $\begin{array}{l}\text { Early morning: } \\
2: 00-6: 59\end{array}$ & $18 / 251$ & 7.2 (5.0 to 10.1$)$ \\
\hline
\end{tabular}

Sensitivity analyses using different approaches to denominator extrapolation did not produce meaningful differences from the main analysis (see online supplementary tables S2-4). When upper-bound SIPP estimates were used to produce conservative rate calculations among pedestrians using wheelchairs, one comparison (excess risk among 50-64 year olds) was rendered nonsignificant (see online supplementary table S5) but other findings were not significantly affected.
Table 3 Driver and vehicle-level characteristics

\begin{tabular}{|c|c|c|}
\hline & $\mathbf{n}$ & $\%(95 \% \mathrm{Cl})$ \\
\hline \multicolumn{3}{|l|}{ Vehicle body type } \\
\hline Automobile & $109 / 237$ & $46.0(41.0$ to 51.1$)$ \\
\hline Light truck & $54 / 237$ & $22.8(18.8$ to 27.4$)$ \\
\hline SUV & $39 / 237$ & 16.5 (13.0 to 20.6$)$ \\
\hline Medium/heavy vehicle & $18 / 237$ & $7.6(5.3$ to 10.8$)$ \\
\hline Van/minivan & $12 / 237$ & $5.1(3.2$ to 7.8$)$ \\
\hline Bus & $3 / 237$ & $1.3(0.5$ to 3.1$)$ \\
\hline Motorcycle & 2/237 & $0.8(0.3$ to 2.5$)$ \\
\hline \multicolumn{3}{|l|}{ Driver's age } \\
\hline Under 30 & $71 / 234$ & $30.3(25.8$ to 35.3$)$ \\
\hline $30-49$ & $77 / 234$ & 32.9 (28.3 to 37.9$)$ \\
\hline $50-64$ & $54 / 234$ & 23.1 (19.0 to 27.7$)$ \\
\hline 65 and over & $32 / 234$ & $13.7(10.5$ to 17.6$)$ \\
\hline \multicolumn{3}{|l|}{ Driver's sex } \\
\hline Female & $59 / 234$ & $25.2(21.0$ to 30.0$)$ \\
\hline Male & $174 / 234$ & 74.8 (70.0 to 79.0$)$ \\
\hline \multicolumn{3}{|c|}{ Police reported substance involvement } \\
\hline Alcohol & 20/252 & 7.9 (5.7 to 11.0$)$ \\
\hline Drugs & $7 / 252$ & $2.8(1.6$ to 4.9$)$ \\
\hline Either alcohol or drugs & $23 / 252$ & 9.1 (6.7 to 12.3$)$ \\
\hline \multicolumn{3}{|l|}{ Driving behaviours } \\
\hline $\begin{array}{l}\text { Failure to yield } \\
\text { right-of-way }\end{array}$ & $54 / 252$ & $21.4(17.7$ to 25.7$)$ \\
\hline Speed-related & $17 / 252$ & 6.7 (4.7 to 9.6$)$ \\
\hline Inattentive driving & $16 / 252$ & 6.4 (4.4 to 9.2$)$ \\
\hline Hit and run & $41 / 252$ & 16.3 (13.0 to 20.2$)$ \\
\hline \multicolumn{3}{|l|}{ Criminal violations } \\
\hline Homicide charge & $10 / 252$ & $4.0(2.5$ to 6.4$)$ \\
\hline $\begin{array}{l}\text { One or more moving } \\
\text { violations }\end{array}$ & $42 / 252$ & 16.7 (13.4 to 20.6$)$ \\
\hline \multicolumn{3}{|l|}{$\begin{array}{l}\text { Crash avoidance } \\
\text { manoeuvers }\end{array}$} \\
\hline None & $146 / 191$ & 76.4 (71.0 to 81.2$)$ \\
\hline Braking & $31 / 191$ & $16.2(12.3$ to 21.2$)$ \\
\hline Steering & $7 / 191$ & 3.7 (2.0 to 6.7$)$ \\
\hline Braking and steering & $6 / 191$ & $3.1(1.6$ to 6.1$)$ \\
\hline Other & $1 / 191$ & 0.5 (0.1 to 2.7$)$ \\
\hline
\end{tabular}

When pedestrian crash mortality in the general population was based on FARS data instead of WISQARS, no findings from the main analysis were significantly affected (see online supplementary table S6). In the second analysis of sensitivity to alternate calculations of general pedestrian mortality risk-increasing the estimated number of pedestrian deaths from WISQARS by $5 \%$ to account for injury deaths with unknown aetiology - excess risk for 50-64 year-olds was rendered marginally significant $(\mathrm{p}=0.08)$; no other meaningful changes were observed (see online supplementary table 7 ).

\section{DISCUSSION}

This is the first study to assess pedestrian death risk among wheelchair users in comparison to the overall population. It finds that the risk of pedestrian crash death is significantly higher for pedestrians who use wheelchairs than those who do not. This differs from 
Table 4 Pedestrian characteristics

n

$\%(95 \% \mathrm{Cl})$

\section{Age}

Under 30

30-49

50-64

Sex

65 and over

Female

Male

Race/ethnicity

White, not Latino

Black, not Latino

Latino, any race

Other

Died at crash scene

$8 / 252$

$44 / 252$

$97 / 252$

$103 / 252$

$3.2(1.9$ to 5.4$)$

17.5 (14.1 to 21.5$)$

38.5 (33.9 to 43.3$)$

40.9 (36.2 to 45.7$)$

$54 / 252 \quad 21.4$ (17.7 to 25.7$)$

$198 / 25278.6$ (74.3 to 82.3 )

$126 / 194 \quad 64.9$ (59.1 to 70.4$)$

$40 / 194 \quad 20.6$ (16.2 to 25.8$)$

20/194 10.3 (7.2 to 14.5$)$

$8 / 194 \quad 4.1$ (2.3 to 7.3 )

66/252 26.2 (22.2 to 30.7 )

Police reported substance involvement

Alcohol

$28 / 252$

Drugs

$6 / 252$

Either alcohol or drugs

29/252 11.5 (8.8 to 15.0$)$

Crosswalk use-intersection crash

Using crosswalk

$57 / 120 \quad 47.5$ (40.6 to 54.5$)$

Crosswalk unavailable

$22 / 120$

$25 / 120 \quad 20.8$ (15.7 to 27.1 )

Not using available

crosswalk

Crosswalk availability

unknown

Outside trafficway $\quad 3 / 120$

Crosswalk use-non-intersection crash

Using crosswalk

$6 / 132$

Crosswalk unavailable

$30 / 132$

$71 / 132$

Not using available

$16 / 132 \quad 12.1(8.4$ to 17.2$)$

Crosswalk availability

unknown

Outside trafficway $\quad 9 / 132$

Contributing factors reported by police

Not visible

$38 / 246$

Dart/dash into street

$10 / 246$

$89 / 246$

Failure to yield/improper

crossing

Prohibited road use

Wheelchair type

Electric

$19 / 246$

Manual or not reported

$169 / 252 \quad 67.1$ (62.4 to 71.5$)$

$83 / 252 \quad 32.9$ (28.5 to 37.6$)$

recent morbidity studies, which did not find increased risk, perhaps because wheelchair use was underascertained in that study's data. ${ }^{7}$ Mortality risk is concentrated predominantly among middle-aged wheelchair users and males, and these patterns are broadly consistent with previous findings from both morbidity and mortality studies. ${ }^{7} 10$

Several factors were common in fatal crashes. The pedestrian environment was often poor. A high percentage of intersection crashes occurred at locations with no traffic controls. Approximately $20 \%$ of crashes-both intersection and non-intersection crashes-occurred at locations lacking crosswalks. Among intersection crashes, about half involved wheelchair users in a crosswalk, which may indicate poor pedestrian infrastructure design in some instances. That crashes frequently were attributed by police to a driver's failure to yield right-of-way underscores the challenges faced by pedestrians who use wheelchairs as they seek to safely using existing pedestrian infrastructure. The potential role played by low conspicuity of wheelchair users is consistent with two findings: police attribution of $15 \%$ of crashes to the wheelchair rider not being sufficiently visible, and three-quarters of crashes involving no driver avoidance manoeuver.

\section{Limitations}

This study has limitations. The first-a problem with all two-sample capture-recapture studies-is that estimates rely on assumptions which cannot be directly assessed, and which, have previously been found to be problematic for injury morbidity studies, though likely less so for mortality. ${ }^{25} 28{ }^{29}$ First, accuracy depends on accurate matching between data sources. ${ }^{24}$ It is impossible to prove that no errors in matching occurred, but the fact that FARS is a fatality census enables partial testing of this assumption. Nearly every news-registry case that was not originally matched to a FARS wheelchair-related case was subsequently able to be matched to a case in the FARS census not coded as involving a wheelchair user, which it suggests that non-matching was likely accurate.

The second assumption-that for any source, any member of the population has equal probability of capture-cannot be directly assessed. However, it is possible to determine whether each sample is representative of the same population by testing for significant differences between the two samples. As noted above, the samples appear to be drawn from the same population, which provides at least some confidence that the second assumption is met. Prior research suggests that news-based surveillance of non-fatal injury tends to have significant sampling bias, but it appears to be representative for fatal injury. ${ }^{13} 30-33$

The last assumption-that the samples are independent-is not directly testable without more than two data sources. The most cause of source dependence is that police reports are the basis of FARS inclusion and also, in some towns, news stories about traffic deaths. This could mean that crashes for which no police report was filed-which should be rare for fatalities-would be excluded from possible capture. In turn, this would result in an underestimate of pedestrian deaths among wheelchair users, which is not a threat to the paper's general finding of elevated risk among pedestrians who use wheelchairs.

The other source of potential misestimation is that the news search strategy may have excluded some wheelchair users if the news report referred to their wheelchair as a 'scooter.' This is because it was often impossible to distinguishing between mobility scooters, mopeds, and 
other devices colloquially called scooters. The effect of this exclusion is to conservatively estimate pedestrian fatalities among wheelchair users.

Finally, there is a possibility of error in MR comparisons-either because of misestimation of the number of people who use wheelchairs or because of misestimation of the number of pedestrian deaths in the general population. However, as shown above, this study's main findings are robust to the plausible range of error in both of these estimates.

\section{Policy implications}

This study extends prior research which suggests that improving pedestrian safety for people using wheelchairs should be a policy priority. Some improvements are general to road safety: reducing distracted driving and pedestrian activity, improving safe crossing behaviour, reducing incapacitated driving, and improving pedestrian infrastructure-all of which appear to have played a role in a significant number of fatal crashes identified in this study. Others are specific to pedestrian risks faced by wheelchair users: low conspicuity of the wheelchair and pedestrian infrastructure that is particularly ill-suited to pedestrians who use wheelchairs.

Modern approaches to disability conceive of it as an interaction between physical limitation and social or environmental factors. ${ }^{34}$ This approach is reflected in the U.S. through the Americans with Disabilities Act, which requires public settings to be accessible to persons with disabilities-including through safe pedestrian infrastructure $^{335}$-and which favours full community integration for people with disabilities. ${ }^{36}$ Prior research has shown that pedestrian safety concerns limit the ability of wheelchair users to fully access their communities, ${ }^{37}$ in violation of these norms, underscoring a substantial justice dimension to the disparities identified in this research.

\section{CONCLUSION}

This study has identified a significant disparity in road crash mortality risk between pedestrians who use wheelchairs and those who do not. These findings underscore the need for policymakers and planners to fully incorporate disability accommodations into pedestrian infrastructure and for persons who use wheelchairs-and others with disabilities-to remain a salient population when road safety interventions are designed. Finally, additional research to better understand would be valuable to better understand what causes the disparities identified in this study.

Contributors JDK and CSB conceived the study and collected data. JDK analysed the data and wrote the first manuscript draft. CSB revised the manuscript critically for intellectual content. Both authors approve the paper's final version.

Funding This research received no specific grant from any funding agency in the public, commercial, or not-for-profit sectors.

Competing interests None declared.
Provenance and peer review Not commissioned; externally peer reviewed.

Data sharing statement FARS and SIPP data are publicly available from NHTSA and the US Census Bureau, respectively. All other data used in this study are available from the corresponding author on request.

Open Access This is an Open Access article distributed in accordance with the Creative Commons Attribution Non Commercial (CC BY-NC 4.0) license, which permits others to distribute, remix, adapt, build upon this work noncommercially, and license their derivative works on different terms, provided the original work is properly cited and the use is non-commercial. See: http:// creativecommons.org/licenses/by-nc/4.0/

\section{REFERENCES}

1. National Highway Traffic Safety Administration. Traffic Safety Facts: 2012 Data. Washington DC: NHTSA, 2014. Report No.: DOT HS 811888

2. Centers for Disease Control and Prevention (CDC). Motor vehicle traffic-related pedestrian deaths-United States, 2001-2010. MMWR Morb Mortal Wkly Rep 2013;62:277-82

3. U.S. Access Board. Proposed accessibility guidelines for pedestrian facilities in the public right-of-way: technical requirements. Fed Regist 2011;76:44664-98.

4. Vision Zero. Pedestrian Safety Action Plan Manhattan. http://www. nyc.gov/html/dot/downloads/pdf/ped-safety-action-plan-manhattan. pdf (accessed 6 Aug 2015).

5. Pedestrian Safety: A Road Safety Manual for Decision-Makers and Practitioners. http://apps.who.int/iris/bitstream/10665/79753/1/ 9789241505352_eng.pdf (accessed 5 Aug 2015).

6. Transportation equity: ensure access to all modes of transportation http://www.unitedspinal.org/positions/transportation-equity-2014.pdf (accessed 15 Jul 2014)

7. Kraemer JD. Epidemiology of non-fatal US emergency room visits for road crashes involving pedestrians in wheelchairs. Inj Prev 2015;21:331-4.

8. Nemire K. Wheelchair conspicuity at night. Proc Hum Factors Ergon Soc Annu Meeting 2010;54:743-7.

9. National Highway Traffic Safety Administration. Wheelchair users injuries and deaths associated with motor vehicle related incidents. Research Note. Washington DC: National Center for Statistics \& Analysis, 1997.

10. LaBan MM, Nabity TS Jr. Traffic collisions between electric mobility devices (wheelchairs) and motor vehicles: accidents, hubris, or self-destructive behavior? Am J Phys Med Rehabil 2010;89:557-60.

11. Kirby RL, Ackroyd-Stolarz SA. Wheelchair safety-adverse reports to the United States Food and Drug Administration. Am J Phys Med Rehabil 1995;74:308-12.

12. Ummat S, Kirby RL. Nonfatal wheelchair-related accidents reported to the National Electronic Injury Surveillance System. Am J Phys Med Rehabil 1994:73:163-7.

13. Baullinger J, Quan L, Bennett E, et al. Use of Washington State newspapers for submersion injury surveillance. Inj Prev 2001;7:339-42.

14. National Highway Traffic Safety Administration. Fatality Analysis Reporting System (FARS) Analytical User's Manual 1975-2013. 2014 December 2014; Report No.: DOT HS 812092.

15. Survey of Income and Program Participation: Methodology. http:// www.census.gov/programs-surveys/sipp/methodology.html (accessed 20 Jan 2015).

16. Survey of Income and Program Participation: Sampling Error. https:// www.census.gov/programs-surveys/sipp/methodology/ sampling-error.html (accessed 1 Nov 2014).

17. Web-based Injury Statistics Query and Reporting System: Fatal Injury Reports. http://www.cdc.gov/injury/wisqars/fatal_injury_reports. html (accessed 15 Dec 2014).

18. Data Sources for WISQARS Fatal. http://www.cdc.gov/injury/ wisqars/fatal_help/data_sources.html (accessed 1 Dec 2014).

19. Chapman $\mathrm{DG}$. Some properties of the hypergeometric distribution with applications to zoological sample censuses. University of California Press, 1951.

20. Razzak JA, Luby SP. Estimating deaths and injuries due to road traffic accidents in Karachi, Pakistan, through the capture-recapture method. Int J Epidemiol 1998;27:866-70.

21. Vong S, Goyet S, Ly S, et al. Under-recognition and reporting of dengue in Cambodia: a capture-recapture analysis of the National Dengue Surveillance System. Epidemiol Infect 2012;140:491-9.

22. Brittain $\mathrm{S}$, Böhning $\mathrm{D}$. Estimators in capture-recapture studies with two sources. AStA Adv Stat Anal 2009;93:23-47. 
23. Abegaz $\mathrm{T}$, Berhane $\mathrm{Y}$, Worku A, et al. Road traffic deaths and injuries are under-reported in Ethiopia: a capture-recapture method. PLOS ONE 2014;9:e103001.

24. Hook EB, Regal RR. Capture-recapture methods in epidemiology: methods and limitations. Epidemiol Rev 1995;17:243-64.

25. Jarvis SN, Lowe PJ, Avery A, et al. Children are not goldfish-mark/ recapture techniques and their application to injury data. Inj Prev 2000;6:46-50.

26. Vyrostek SB, Annest JL, Ryan GW. Surveillance for fatal and nonfatal injuries-United States, 2001. MMWR Surveill Summ 2004;53:1-57.

27. Finkelstein EA, Corso PS, Miller TR. Fatalities. The Incidence and Economic Burden of Injuries in the United States. New York: Oxford University Press, 2006:35-7.

28. Samuel JC, Sankhulani E, Qureshi JS, et al. Under-reporting of road traffic mortality in developing countries: application of a capture-recapture statistical model to refine mortality estimates. PLOS ONE 2012;7:e31091.

29. Morrison A, Stone DH. Capture-recapture: a useful methodological tool for counting traffic related injuries?. Inj Prev 2000;6: 299-304.
30. Malphurs JE, Cohen D. A newspaper surveillance study of homicide-suicide in the United States. Am J Forensic Med Pathol 2002;23:142-8

31. Villela $L$ de $C$, Rezende EM, et al. Use of the printed press for qualification of external causes of death. Rev Saude Publica 2012;46:730-6.

32. Rosales M, Smith SA, Stallones L. Newspaper coverage of injuries affecting the Spanish surname population in two counties in Colorado. Psychol Rep 2006;99:651-8.

33. Rainey DY, Runyan CW. Newspapers: a source for injury surveillance?. Am J Public Health 1992;82:745-6.

34. Sen A. Capabilities and Resources. The Idea of Justice Cambridge. MA: Harvard University Press, 2009:253-68.

35. U.S. Department of Justice. Curb ramps and pedestrian crossings. http://www.ada.gov/pcatoolkit/chap6toolkit.htm. 7 May 2007. (accessed 30 Apr 2015).

36. Olmstead v. LC. 527 U.S. 581, 1986. https://www.law.cornell.edu/ supct/html/98-536.ZS.html (accessed 30 Apr 2015)

37. Mortenson WB, Miller WC, Boily J, et al. Perceptions of power mobility use and safety within residential facilities. Can J Occup Ther 2005;72:142-52. 